\title{
Is there a convincing case for climate veganism?
}

\author{
Teea Kortetmäki ${ }^{1,2}$ (1) Markku Oksanen ${ }^{3}[0$
}

Accepted: 21 November 2020 / Published online: 6 December 2020

(c) The Author(s) 2020

\begin{abstract}
Climate change compels us to rethink the ethics of our dietary choices and has become an interesting issue for ethicists concerned about diets, including animal ethicists. The defenders of veganism have found that climate change provides a new reason to support their cause because many animal-based foods have high greenhouse gas emissions. The new style of argumentation, the 'climatic argument(s) for veganism', may benefit animals by persuading even those who are not concerned about animals themselves but worry about climate change. The arguments about the high emissions of animal-based food, and a resulting moral obligation to abstain from eating such products, are an addition to the prior forms of argument for principled veganism grounded on the moral standing of, and concern for, nonhuman animals. In this paper, we examine whether the climatic argument for veganism is convincing. We propose a formulation for the amended version of the argument and discuss its implications and differences compared to the moral obligations of principled veganism. We also reflect upon the implications of our findings on agricultural and food ethics more generally.
\end{abstract}

Keywords Climate ethics $\cdot$ Food ethics $\cdot$ Low-carbon diets $\cdot$ Ethical eating $\cdot$ Food waste $\cdot$ Animal ethics

\section{Introduction}

Our dietary choices matter greatly for climate change related ethical considerations. Food production, processing, and consumption activities contribute approximately to $30 \%$ of human-caused climate emissions and aggravate other environmental problems like freshwater withdrawal, nutrient pollution, and biodiversity degradation (Clark et al. 2019). This makes food systems a significant issue for climate mitigation. ${ }^{1}$ Particular attention has been paid to cattle, who are estimated to cause approximately half of the food related climate emissions due to land use impacts and methane produced by ruminating animals. The overall average difference between the climate impacts of animal-based and

Teea Kortetmäki

teea.kortetmaki@jyu.fi

Markku Oksanen

markku.oksanen@uef.fi

1 Department of Social Sciences and Philosophy, University of Jyvaskyla, PO Box 35, 40014 Jyvaskyla, Finland

2 School of Resource Wisdom, University of Jyvaskyla, PO Box 35, 40014 Jyvaskyla, Finland

3 Department of Social Sciences, University of Eastern Finland, PO Box 1627, 70211 Kuopio, Finland plant-based food is perceived to be significant and the difference in emissions between ruminant meat and plant-based food may even be 100-fold (Poore and Nemecek 2018; Clark and Tilman 2017). ${ }^{2}$ Henceforth, both activist and research voices call for cutting down meat and dairy consumption by means of policy measures such as a meat tax (Wirsenius et al. 2011) and dietary approaches like a 'planetary health diet' (Willett et al. 2019). Joseph Poore, the lead author of a much cited Science article on the matter (Poore and Nemecek 2018), pointed out that "a vegan diet is probably the single biggest way to reduce your impact on planet Earth, not just greenhouse gases, but global acidification, eutrophication, land use and water use" (Petter 2018). ${ }^{3}$ This is in line

\footnotetext{
${ }^{1}$ A food system involves supply chains (from farm to fork) and activities that directly influence supply chains, like food policy. Food system emissions usually include supply chain emissions: the production, processing, transportation, retail, and consumption of food, including the emissions from the land use impacts of agriculture and food waste emissions.

2 'Animal-based food' refers to edible goods that intentionally contain animal ingredients. Food that unintentionally contains material from non-plant sources (insects, birds, or small mammals that 'pollute' crops in harvesting accidents) still counts as plant-based.

3 The quote was stated in the Independent feature 'Veganism is 'single biggest way' to reduce our environmental impact on planet, study finds' (June 1, 2018): https://www.independent.co.uk/life-style/healt h-and-families/veganism-environmental-impact-planet-reduced-plant -based-diet-humans-study-a8378631.html.
} 
with a much earlier statement by the ethicist Brian G. Henning (2011, p. 86) that "the morality and sustainability of one's diet are inversely related to the proportion of animals and animal products in one's diet".

Animal activists and theorists have seized the opportunity to advocate their cause with climatic arguments that may persuade even those who are not convinced by animal-centred moral arguments for veganism. At the moment of writing, websites like climatevegan.org and thesavemovement. org explicitly state that the adoption of a vegan diet is a critical part of climate actions. People for the Ethical Treatment of Animals (PETA) has adopted climatic arguments stating that "Of course, eating vegan foods rather than animal-based ones is the best way to reduce your carbon footprint." legal scholar and radical animal rights advocate Gary L. Francione argues, "The bottom line is clear: we are facing imminent disaster. If we really want to save the planet from climate catastrophe, we must promote a grassroots effort with a clear normative directive: stop eating animal products and adopt a vegan diet." 5

Climatic arguments for veganism have not been critically analysed. Yet, it is not obvious that climatic arguments result in moral obligations identical with the obligations that arise from animal-centred arguments for principled or 'list-of-ingredients' veganism as it is most commonly understood. ${ }^{6}$ In this article, we investigate to what extent veganism can rest on the argumentation from anthropogenic climate change. We approach the issue by asking: what would a convincing argument for the moral obligation to a low-carbon diet look like and what are its dietary implications, compared to animal-centred, principled veganism? We aim to show how the arguments from climate change for veganism are vulnerable to certain weaknesses and do not always support choices obliged by animal-centred arguments for veg*nism. ${ }^{7}$ However, this does not rule out that

\footnotetext{
${ }^{4}$ https://www.peta.org/issues/animals-used-for-food/global-warming/ (visited 12 Sept 2020; the other webpages mentioned were visited in September 2020).

5 https://medium.com/@gary.francione/vegan-or-die-the-impor tance-of-confronting-climate-change-c08e31e56db8 (visited $16 \mathrm{Sept}$ 2020).

${ }^{6}$ Veg*n obligations are commonly understood to imply a list of prohibited foods, resulting in a kind of 'list-of-ingredients' approach to food choices (Lamey 2019, p. 65).

7 When we discuss at a more general level or refer to earlier philosophical discussions (that often talk about vegetarianism), we speak of veg*nism to refer to different diets involving abstinence from at least some animal-based foods. We do not consider the impacts of agricultural production methods or inputs like manure though the 'full' veganisation of the food system would imply, among other things, animal-free fertilisation. Moreover, we focus on food and do not consider other (e.g. clothing-related) aspects of veganism.
}

animal-centred arguments for veg*nism can be a justifiable normative approach to food ethics for other than climatic reasons.

The public discussion has witnessed arguments for both vegetarian and vegan dietary choices because of climate change (as well as more flexible demands for reducing meat consumption). To complicate the terminology, philosophical arguments for veg*nism have historically been leaning towards obliging vegetarianism, even when the argumentation itself quite clearly implies vegan consequences (e.g., Wenz 1984), whereas the recent debate commonly involves the endorsement of veganism. We focus on veganism for several reasons: animal movements that have adopted the climatic arguments often promote veganism; the vegan diet has been present in public discussion and raises more objections than other proposals due to its demandingness; and veganism is empirically sounder than vegetarianism regarding the climate impacts of diets. ${ }^{8}$

\section{The conventional ethical arguments for veganism}

The conventional or 'traditional' ethical arguments for veg*n diets appeal either to the benefit or harm (of various dietary choices) to humans or, more commonly, to the harm to animals used for food. ${ }^{9}$ The human-centred arguments have come in many forms, from ideas of moral integrity or excellence to visions of kinship (on ancient views, Newmyer 2006, pp. 19-21; on modern views, Abbate 2019a, pp. 557-558), to ideas of positive societal impacts, like 'freeing' land from feed production to edible crops or for other uses (Sandler 2015). ${ }^{10}$ The animal-centred arguments allege that eating animals is wrong independently of the consequences to humanity. This reasoning has been grounded on two distinct lines of justification, utilitarian and (neo-)Kantian (though Kant himself is considered an anthropocentrist who condemns cruelty to animals on human-centred grounds; see Kain 2018).

Utilitarianism builds on the principle that takes seriously "the greatest happiness of all sentient beings", as

\footnotetext{
8 Validity refers to the logical consistency of an argument, soundness to the empirical truth value of its elements. A recent meta-analysis (Poore and Nemecek 2018) estimates the mean GHG impacts $\left(\mathrm{CO}_{2} \mathrm{eq} / 100 \mathrm{~g}\right.$ protein $)$ of cheese and eggs to be 11 and $4.2 \mathrm{~kg}$, respectively, whereas the mean emissions of all compared plant protein products (tofu, groundnuts and nuts, legumes) are $\leq 2.0 \mathrm{~kg}$.

${ }^{9}$ Ethical arguments appeal to the consequences of an action for others whereas prudential arguments appeal to self-interest.

10 The land use point resembles ecocentric requests to decrease agricultural land use to protect wilderness or other characteristics of a non-cultivated landscape.
} 
Henry Sidgwick (1906, p. 431) maintains: roughly put, it is a moral duty to maximise overall good in the world and the interests of all sentient beings count in this calculation. The consideration of sentient beings in utilitarianism does not necessarily prohibit meat-eating and killing categorically, since calculation concerns the sum of individuals' happiness resulting from actions: unless non-utilitarian limitations for acceptable outcomes are introduced, the killing of one animal for the gustatory pleasure of, let's say, ten people results in a greater sum of overall happiness. Peter Singer has famously defended the view that utilitarian considerations imply the moral obligation for veg*nism (Singer 1980, 2016); however, it has been suggested that, at some points, Singer permits eating painlessly killed meat. ${ }^{11}$ In short, the utilitarian argument for veg*nism states that because (1) animals can suffer, (2) it is wrong to cause avoidable suffering, and (3) eating meat causes avoidable suffering, eating meat (or animal-based food in the vegan argument) is wrong. The argument has been criticised as being impotent: "the seemingly indisputable fact that our individual purchases rarely actually yield positive (or negative) consequences to[sic] the good (and bad) agricultural and labour practices we mean to affect" (Almassi 2011, p. 397). Here we assume that the impotence objection has been sufficiently addressed to make consequentialist reasoning for ethical, animal-centred arguments for veg*nism meaningful (Norcross 2004, pp. 232-33; Almassi 2011; see also Morgan-Knapp and Goodman 2015 for similar points in climate ethics).

In the (neo-)Kantian view, animals are experiencing subjects-of-a-life and have thereby inherent value and the right to be treated in a way that respects their inherent value. Meat-eating violates that right; thus, "vegetarianism is not supererogatory; it is obligatory" (Regan 1988, p. 346). Respecting the moral value of nonhuman animals means treating them not "as a mere means to your own ends" (Korsgaard 2018, p. 223). Some authors suggest this implies abstinence from eating meat (Goodnick 2015), whereas others argue it implies veganism since the production of any animal-based food treats animals as mere means.

In both utilitarian and Kantian forms, animal-centred veg*nism is a self-standing moral stance. Its justification needs no climatic or other additional arguments (though it allows them, and many may be veg*ns for several reasons). Its conclusions are non-contextual and applicable to all situations.

Animal-centred ethical argumentation has convinced a relatively small audience outside the (few) traditionally

\footnotetext{
11 See Lamey 2019 (Chapter 5) for the debate. Singer argues for vegetarianism in his earlier works but does not address dairy production (among other things). The status of insects remains unclear, too. Singer's more nuanced views are not relevant for our examination.
}

veg*n cultures and religions: actual practices have changed only little. It is therefore not surprising that the potential of climate-change-based arguments for helping spread vegan practices have been happily welcomed by many animal ethicists and animal rights advocates. Climate change could provide arguments for achieving effects these groups have been striving for but which appeal to a broader audience: namely, those who are not convinced about the moral stance of individual animals (and who may be interested solely in human beings and humanity), yet are concerned about climate change. However, has this argumentative addition been inferred too hastily from general empirical observations? Does climate change provide a foundation for promoting veg*nism in the sense endorsed by animal ethicists? Is there a convincing case for climate veganism and are its arguments and implications similar or different from the conventional, animal-centred arguments for veg*nism?

\section{Analysing the 'climatic argument for veganism'}

By the 'climatic argument for veg*nism', CAV for short, we refer to the argument that essentially appeals to anthropogenic climate change in defence of the claim that one has a moral obligation to be a veg*n. The essential appeal means that the argument is contingent on climate-related, scientifically verifiable views. If climate change were suddenly resolved, or the atmosphere started cooling down due to natural causes, or the connection between food choices and their climatic impacts were no longer true, the CAV would no longer hold. An important consideration is that while CAV relies essentially on climatic concerns in its formulation, motivations behind it are diverse: a distinction can be made between 'animal-motivated CAV', where animal protection advocates add climatic reasons to their argumentative toolbox, and 'environment/human-motivated CAV', where the motivation for veganism on climatic grounds rests primarily on concerns for the impacts of climate change on humans and/or the environment.

Climate ethics has yielded a rich discussion on the moral duties of individuals regarding climate change (e.g., Sinnott-Armstrong 2005; Voget-Kleschin et al. 2019). Climatic duties are generally grounded on the premise that anthropogenic climate change has overall negative consequences for present and future humans. Reasoning about climatic duties is generally based on human self-concern and is also prudential; human-centredness manifests in much of the public discussion on climate change and in the IPCC and UN statements (McShane 2016). Some (but not many) ethicists have recently brought non-anthropocentric tones to the climate ethics discussion by addressing the suffering of nonhumans 
due to climate change (Henning and Walsh 2020; Pepper 2019). ${ }^{12}$

Structurally, the CAV can be assumed to resemble other ecologically concerned arguments for veg*nism (Wenz 1984; Taylor 1986; Sandler 2015) that are mainly consequentialist and grounded on concerns for the impacts of human food production on ecosystem health (Wenz 1984) and land use (cf. Taylor 1986). ${ }^{13}$ Sandler (2015, p. 87) summarises the ecological argument as follows: "EP1. We ought to act in ways that reduce the ecological impacts of our diet. EP2. Adopting a non-meat diet would significantly reduce the ecological impacts of our diet. EC3. Therefore, we ought to adopt a non-meat diet." However, the climatic aspect calls for an immediate revision, because although cheese is not meat, it has one of the highest GHG footprints among foods and is common in non-meat diets. This is also noted by the advocates of climate veg*nism whose statements were presented in the introduction. Following those statements, the climatic argument for veganism (CAV) would have the following structure:

CAV-P1 We ought to act in ways that significantly ${ }^{14}$ reduce the climatic impacts of our diet.

CAV-P2 Animal-based foods have significantly high climatic impacts.

CAV-C Therefore: we ought to adopt a vegan diet.

In this form, the CAV argument arranges in a formal demonstration the statements made by vegan advocacy sites and public figures known for previously advocating strict principled veganism and/or animal rights (see the Introduction) and now advocating veganism for climatic reasons; their argument represents 'animal-motivated CAV'. The CAV can also be adopted by anyone who is concerned about the impacts of climate change on humans or nature generally ('environment/human-motivated CAV') like Joseph Poore who stated in the Independent interview that "a vegan diet is probably the single biggest way to reduce your impact on planet Earth, not just greenhouse gases". Both camps advocate a vegan diet on similar, climatic grounds.

Two features of the CAV are worth noting now. First, the argument has both normative and empirical premises, which is typical in applied ethics. Its soundness depends

\footnotetext{
12 These aspects have received little attention compared to the concern about humanity (Korsgaard 2018, p. 194).

13 Taylor's account is mainly deontological, yet he also appeals to the land use impacts of diets.

14 We will later discuss what'significant reduction' means. The advocates of climatic veganism, quite clearly, talk neither about just any reductions (for that would be insufficient and would not imply any kind of veganism), nor about minimizing one's dietary emissions (for that would require very difficult asceticism).
}

on the validity of the argument, the intuitive force of the normative claims and the truth value of empirical premises. For empirical reasons, the argument necessarily remains open to alternative conclusions that we discuss later. ${ }^{15}$ Second, the argument assumes that the duties entailed by climate-friendly diets are negative (duties of abstinence): eating certain foods is morally prohibited because of their climatic impacts. This kind of approach is common to ethical dietary guidelines. Whether climatic arguments could also yield positive dietary duties ('eat your potatoes!') has not been studied to our knowledge, though positive duties have occasionally been discussed in animal-concerned food ethics in suggestions that the usual arguments for veg*nism actually imply obligations to consume and collect roadkill (Bruckner 2016, p. 43) or to enrich vegan diets with some meat for the animals' sake (for further introduction and critical examination of these views, see Lamey 2019).

What can be said about the CAV? We assume that individuals' dietary choices have been proven to be a significant matter of moral considerations in food (and climate) ethics and we do not question that point. However, the CAV is unconvincing and even unsound in the above form (the use of 'vegetarian' in the conclusion would make it even more so). Next, we elaborate some problems regarding the CAV, amend the argument to make it more convincing and sound, compare the new amended argument with the initial formulation and reflect upon the implications of the revision from the viewpoint of the proponents of climate veganism.

\section{Underdetermination}

P2 of the CAV, "Animal-based foods have significantly high climatic impacts", is empirically untrue: not all animalbased foods have high climatic impacts. Sustainable freshwater and ocean fish catches, as well as the most sustainably produced liquid dairy products and insects, have a carbon footprint that is close or equal to or even lower than average plant-based proteins. ${ }^{16}$ The same point regarding general environmental impacts was noted in the first versions of the ecological argument for veg*nism (Wenz 1984). Consequently, veganism is not the only reasonable conclusion from $\mathrm{P} 1$. The challenge lies in the fact that the continuums of the carbon footprints of vegan and non-vegan products overlap,

\footnotetext{
15 The same applies to utilitarian arguments for veg*nism that are grounded on the obligation not to inflict suffering: the invention of 'totally suffering-free' meat production would make the argument lose its power.

${ }^{16}$ For example, the estimated emissions $\left(\mathrm{CO}_{2} \mathrm{eq} / 100 \mathrm{~g}\right.$ of protein) of Norwegian mackerel and herring are ca. $0.6-0.7 \mathrm{~kg}$ (Ziegler et al. 2013) whereas that of tofu is $2.0 \mathrm{~kg}$ (Poore and Nemecek 2018). Even moderate margins of error do not change the point.
} 
even if the average emissions of these product groups differ significantly (see also Budolfson 2015). ${ }^{17}$

What is more, future food production developments might challenge the CAV. Consider the possibility of some meat production to become relatively low- or even zero-carbon. This is not a mere fantasy: some big ruminant operators in the food industry, with governmental support, have already announced aims to become carbon neutral. ${ }^{18}$ This development would appear uncomfortable to the animal-motivated CAV: the emergence of low-/zero-carbon meat would turn the argument they have used against their initial purpose, implying that climatic concerns still allow (or perhaps even support) the consumption of certain meats.

A potential response is that expecting any animal production to become low- or zero-carbon is unrealistic. Moreover, because climate change materialises quickly, it may still be better to significantly reduce or even give up raising animals for food in industrialised countries to have immediate effects, instead of technological solutions that require time to develop and still may have their limitations (see also Henning 2011). Yet, the risk persists that the CAV would lose its power as soon as technological solutions emerged. Nevertheless, the first counterexample of the already existing low-carbon animal-based foods suffices to make the CAV underdetermined for obliging a vegan diet.

Another aspect that relates to underdetermination and challenges the persuasiveness of the CAV rests on the relative insignificance of occasional dietary choices. According to this line of thought, even if the premise, "Animal-based foods have significantly high climatic impacts", were generally true, the conclusion, "Therefore: we ought to adopt a vegan diet", does not convincingly follow. We next discuss some counterexamples that bear real-world relevance.

A vegan diet is commonly defined on a 'list-of-ingredients' basis, as principled abstinence from food items of animal origin (Lamey 2019, p. 65). ${ }^{19}$ This also excludes the food industry additives like gelatine, colouring agents, and beeswax, and ingredients used in such tiny amounts that they comprise a small percentage of the final product (like

\footnotetext{
17 The advocates of an omnivorous yet low-carbon diet may want to emphasise that 'animal products' is too general as a category: mean emissions of the highest-impact animal products are more than ten-fold compared to those of lower-impact products (Poore and Nemecek 2018).

18 See, for example, news in Finland, https://www.valio.com/articles/ valio-aims-at-carbon-neutral-dairy-by-2035/, and in New Zealand, https://www.theguardian.com/world/2020/jan/01/from-red-seaweedto-climate-smart-cows-new-zealand-leads-the-fight-against-methane

19 Similar definitions, based on categorical abstinence from all products of animal origin, are provided for 'vegan' in, for example, the Cambridge English and Merriam-Webster dictionaries and PeTA web page. Lamey (2019) prefers defining veganism in terms of harm reduction but acknowledges that this is a less common approach.
}

honey, butter, or a splash of coffee milk). Given the amount of food an individual eats daily, it is unconvincing to argue that coffee milk or honey would make any significant difference on the climatic impacts of one's diet. ${ }^{20}$ The animalconcerned and environment/human-concerned proponents of the CAV likely differ in their views here: the latter likely see no problem with calling a diet vegan while allowing such deviations. However, the animal-concerned proponents of the CAV who have previously been arguing for principled and strict list-of-ingredients approach to veganism, or veganism in its commonly defined sense, may struggle to give in to such deviations, for that would require them to loosen their definition of veganism.

Another counterexample concerns 'occasional carnivorism' and can best be explained with a simple calculation based on the mean GHG $\left(\mathrm{CO}_{2}\right.$ eq) emissions listed in the meta-analysis (Poore and Nemecek 2018, p. 988). The emissions of a small, 100-g piece of chicken (approximately $1.15 \mathrm{~kg} \mathrm{CO}_{2}$ eq) equals the emissions of approximately $1.1 \mathrm{~L}$ of soymilk or $500 \mathrm{~g}$ of tomatoes. Given that the average individuals' GHG emissions in the OECD countries are around 9 t/a or nearly $25 \mathrm{~kg} / \mathrm{day},{ }^{21}$ eating a bit of chicken once a week does not significantly influence one's overall emissions, even with ambitious emission reduction schemes. (Acknowledgedly, a similar piece of beef or cheese, be it local or not, ${ }^{22}$ would have a multifold carbon footprint.) Animal-centred food ethics may judge occasional carnivorism morally unjustifiable (Almeida and Bernstein 2000; Abbate 2019b). However, the reasons are not applicable to climate concerned choices because climatic reasoning concerns not the wrongness of a single action but the aggregate harm impacts of all actions, or keeping the overall footprint under one's 'harm budget' (cf. Budolfson 2015). ${ }^{23}$ Of course, attention should be paid to the aggregate impacts of the actions of all individuals: there is certainly a limit after which 'occasional carnivorism' (if it can be called occasional anymore) becomes a significant source of climatic emissions.

\footnotetext{
20 This point differs from the impotence objection that questions any significance of individual choices.

21 Year 2016 estimate data, https://data.worldbank.org/indicator/ en.atm.CO2e.pc

${ }^{22}$ One unsound argument against veganism suggests that local meat is environmentally superior to vegan, non-local products. However, transportation matters much less than agricultural phase for the lifecycle emissions of a food product (Poore and Nemecek 2018).

${ }^{23}$ In this sense, climatic reasoning for food ethics clearly represents a consequentialist approach.
} 


\section{Discrepancy: climate-friendly choices in a non-ideal world}

One problematic aspect of the CAV concerns its variants that adhere to (strictly or even relatively) principled definitions of 'veganism'. Different motivations behind the climatic argument for veganism likely yield different definitions of veganism. While environment/human-concerned proponents of the CAV may interpret veganism in more flexible ways, it is reasonable to believe that most animal protection advocates who have previously argued for principled veganism for animal ethical reasons and now harnessed the CAV to support their cause, are less willing to make such deviations from their initial standpoint. ${ }^{24}$ In philosophical animal and food ethics discussions, veganism has also usually been understood as a principled 'list-of-ingredients' approach: this very fact has given rise to debates about the status of dumpster diving meat, roadkill, and so on, based on the consequences of the premises behind vegan conclusions. While the principled approach makes sense from the animal protection viewpoint, principle-like obligations and the best options in the second-best world often conflict in the case of climate-friendly action. The second-best world we inhabit creates numerous situations where choosing the lowest-carbon way to eat conflicts with principled veganism. Food waste provides an example with great environmental significance. Wasted food (about one third of produced food) causes emissions 'for nothing'. Wasting animal-based food is the worst of bad cases: products with a high carbon footprint and nutrient intensity are discarded. Whenever the possibility to prevent food waste occurs, the premise $\mathrm{P} 1$ "We ought to act in ways that significantly reduce the climatic impacts of our diet" should encourage reducing the overall food waste by eating otherwise discarded food, be it animalbased or not, since food waste reduction helps combat climate change. ${ }^{25}$

This is not a problem for the environment/human-motivated $\mathrm{CAV}$, but it is for the animal-motivated $\mathrm{CAV}$, as the case below illustrates. Defending principled vegetarianism, Ben Almassi argues for discarding the 'accidental pepperoni' that has been accidentally added to, say, Peter's vegetarian pizza (Almassi 2011, pp. 407-408). Almassi provides three reasons to throw the meat away: (1) staying consistent with vegetarianism, Peter can advocate vegetarianism more effectively and honestly (cf. Almeida and Bernstein 2000);

\footnotetext{
${ }^{24}$ Admittedly, some animal-concerned vegan advocates follow a less principled interpretation about veganism. Lamey (2019, p. 65) mentions the Vegan Outreach group's founder as one example. These are, however, exceptions rather than a norm in the definition of veganism.

25 Weightier, like health-related, reasons against eating some of the to-be-wasted food may sometimes exist.
}

(2) Peter avoids deceiving himself; and (3) Peter does not risk the consistency of his future actions: deviating from vegetarianism may increase the likelihood of future deviations. We think that none of these factors would require Peter to discard pepperoni in the CAV context. Only the risk of drifting into omnivorism in the future (the gateway drug effect?) could be relevant for climatic considerations though not fully convincing (we acknowledge individual variation). Eating the 'accidental pepperoni' that would otherwise be wasted is consistent from the climatic viewpoint and supports the aim to reduce dietary emissions. We argue that adherence to a climate-friendly diet permits eating meat in such cases (instead of considering that as a self-deception) and may make it even praiseworthy though perhaps not obligatory; this indeed raises the question whether climate responsibilities may evoke prima facie positive duties regarding food actions ('reduce waste', not just 'do not leave food to spoil'), but we leave the question open here. Anyhow, in these situations the permitted courses of action go against veganism as it is commonly understood and endorsed by the animalconcerned proponents of the $\mathrm{CAV} .{ }^{26}$ The unorthodox sources or opportunities for meat-eating are manifold (e.g., Abbate 2019a) and cannot be analysed here in detail, but it seems that the climatic argument permits many of them while the animal concerned arguments do not (Abbate 2019b; Almassi 2011).

\section{Insufficiency objection: veganism is too much but not enough}

Empirical findings confirm that the avoidance of animalbased food improves the climate-friendliness of a diet on average but does not guarantee it, even if we reject the fanciful examples of vegan 'avocadoholics' or the examples that involve cherry- or, rather, quinoa-avocado-berry-picking (Budolfson 2015, p. 170) introduced to debunk arguments for veg*nism motivated by harm reduction. ${ }^{27}$ Because highprotein and high-fat foods, vegan or not, generally have much higher carbon footprints than carbohydrate-based foods (Poore and Nemecek 2018, p. 988), ${ }^{28}$ a vegan diet with lots of fast food can have a high climatic impact even if average vegan diets are much lower-carbon than omnivorous diets (e.g., Scarborough et al. 2014). A further point is that regardless of the product-level emissions, the overall amount

\footnotetext{
${ }^{26}$ A further question is whether climate-related reasons actually in some circumstances create an obligation to, for example, conduct dumpster diving, the most active form of food waste reduction.

${ }^{27}$ No reason exists why an avocado maniac would more likely be a vegan than an omnivore.

${ }^{28}$ Poore and Nemecek use different functional units for protein-rich and carbohydrate-rich foods; numbers cannot be compared without conversion.
} 
of eaten food matters for the overall emissions. Given that most of the adults in the OECD area are overweight or obese - they eat more than they need to satisfy their basic needsthis issue has received surprisingly little attention in food ethics. ${ }^{29}$

Of course, the CAV concerns only one set of prohibited food choices (that which happens to match animal-basedness) even in the list-of-ingredients form. Multiple moral guidelines are often used anyway to inform responsible dietary choices (concerning, for example, social fairness or nationalistic sentiments related to food production). The proponent of the CAV may argue that climatic considerations, too, can evoke additional restrictions. For the CAV argument this means that there would also be additional climate-concerned restrictions, like the 'CAV2' prohibiting carbon-intensive vegan foods. The CAV proponents could thereby present veganism as a necessary but not a sufficient principle for low-carbon eating. This strategy, however, may weaken the persuasiveness of the argument of those who wish to promote principled veganism on the basis of the CAV: it depicts veganism as a demanding yet insufficient principle for climate-friendly eating.

\section{Implications for making the case for climatic veganism sound and convincing}

Above, we discussed problems that reduce the persuasiveness and soundness of the CAV as such. To recapitulate, there are at least two kinds of basic problems. First, the CAV is underdetermined. It does not follow from its premises that a fully vegan diet would be the only way to construct a low-carbon diet. Moreover, the premise "We ought to act in ways that significantly reduce the climatic impacts of our diet" does not oblige the complete exclusion of higher-impact foods (that are often animal-based) due to the overall insignificance of the occasional consumption of higher-impact products. Second, there is a discrepancy between the suggested principles and climate-friendly action in real life. In the second-best world, climate-ideal choices may in some actual circumstances be non-vegan. While this is unproblematic for some CAV proponents, it is uncomfortable for the animal-motivated CAV because the observation even encourages the consumption of non-vegan products in certain circumstances. Third, the obligation of veganism is insufficient for guaranteeing a climate-friendly diet, which may reduce the persuasiveness of the CAV.

\footnotetext{
${ }^{29}$ Whether climate-concerned food ethics should say something about the amount of food eaten is an interesting question but cannot be examined here.
}

In sum, the CAV as an argument for obliged veganism on climatic grounds is unconvincing, regardless of whether it is interpreted strictly, to entail a principled list-of-ingredients type of veganism, or with some flexibility. On the other hand, the problems do not appear to undermine the argument fundamentally but call for revising it. We take these problems into account and suggest a more convincing, amended version of the argument (ACAV):

ACAV-P1 We ought to adopt a diet that is low-carbon (with emissions below the threshold ${ }^{30}$ of a climate-harming diet) to significantly reduce the harmful climatic impacts of our diet.

ACAV-P2 Eating high-impact foods must be restricted so as not to cross the threshold of harmful dietary emissions.

ACAV-P3 Most animal-based foods have high climatic impacts.

ACAV-P4 Most plant-based foods have low or moderate climatic impacts.

ACAV-P5 A predominantly vegan diet is the only way to keep a diet on average below the threshold of a climate-harming diet.

ACAV-P6 There are exceptional circumstances in the second-best world (like reducing the food waste of others) where eating high-impact foods makes no difference or may benefit the climate.

ACAV-C Therefore: we ought to follow a predominantly vegan diet with the permitted exceptions that can be made without crossing the threshold of a climate-harming diet.

The ACAV is sound and consistent with the present empirical information about the climatic impacts of food products and food system activities. It could be labelled 'pragmatic climate veganism' because its rule of thumb is general adherence to veganism. Yet, 'pragmatic' implies that this diet is sensitive to contexts and acknowledges that food emissions comprise a comparative continuum, rather than categories. The ACAV still allows following animal-centred, principled veganism (while moderating the consumption of high-impact vegan foods) — exceptions to veganism are permitted but not required-but does not oblige it. Notably, the ACAV is nevertheless more restricting than a conventional vegetarian diet where cheese products may often serve as

\footnotetext{
$\overline{30}$ Defining this threshold is a task of empirical sciences (combined with normative ones to define 'harmful'). It should consider the overall threshold for individual emissions (emissions per capita to avoid the risk of dangerous climate change) and allocate it reasonably to different spheres of life. The IPCC statement (IPCC 2018) that global emissions should fall by $45 \%$ by 2030 and reach net zero by 2050 illustrates the scale of the needed changes.
} 
a common protein source. This highlights the difference between common vegetarianism and veganism from the climatic viewpoint.

The ACAV may be inconvenient for the proponents of the animal-motivated CAV who are primarily concerned about animals and want to harness climatic arguments for promoting their cause. Climatic concerns do not provide consistent reasons for the exclusion of all non-vegan products and in some circumstances the non-vegan choices may be the most climate-friendly ones available. The proponent of the ACAV also has to accept that in some possible future there may be no climatic reasons to abstain from eating a certain range of animal-based food, if new technological developments radically lower their carbon footprint. ${ }^{31}$ Such changes may not create a positive duty to eat animal-based food, unless that would be the only way to keep one's dietary emissions under the harm budget threshold.

\section{Can the animal-motivated climatic veganism (and the animals) be saved?}

What can those who are primarily concerned about animals respond to the above reasoning? We discuss two potential responses next, one that aligns the argument with the framework of rights and another, more action-oriented response.

\section{Rights First argument: limits to how far one can go in saving the climate}

The Rights First argument maintains that while empirical facts may correctly restrict the permitted foods, they do not justify extending the set of permitted foods to animal-based items. This addition is based on the idea that fundamental, rights-like principles cannot be overridden by consequentialist reasons outside exceptional circumstances. ${ }^{32}$ 'Rights First'-type responses are also relevant for human-centred discourses concerning acceptable climate action (e.g., RohtArriaza 2009). The Rights First argument coheres with the argument of animal rights in the context of climate change adaptation: animal rights may set an action-restricting negative duty not to violate nonhuman rights by adaptation measures (Pepper 2019). Rights are so fundamental that climate

\footnotetext{
31 Voluntary GHG compensation payments (offered by some restaurants) are a different, more problematic case: they do not reduce the emissions of the given activity but are assumed to reduce emissions elsewhere in the future.

32 Our reasoning is applicable in industrialised countries. Exceptional circumstances also require distinct moral reasoning (like Greenland where seal eating may be the only source for food, or arid and poor regions where cattle keeping is the only way to provide food security for one's family)
}

mitigation and adaptation, important as they are, cannot be taken at the cost of violating rights. ${ }^{33}$

The Rights First response implies that we ought to act to reduce the climatic impacts of our diets but only to the extent that doing so does not compromise more fundamental values, that is human and animal rights. The argument for climatic veganism with this addition is as follows:

RFCAV-P1 We ought to act in ways that significantly reduce the climatic impacts of our diet unless doing so compromises fundamental human and animal rights.

RFCAV-P2 Eating animal-based foods violates animal rights.

RFCAV-C Therefore: we ought to adopt a diet that is both low-carbon (with emissions below the threshold of a climate-harming diet) and vegan.

Rights considerations set limits to the role of animal production in the future low-carbon food system. Even low-/ zero-carbon meat production would be morally prohibited because it violates animal rights. The argument remains ambiguous regarding the permitted courses of action in the second-best world where the consumption of animal-based food would help reduce GHG emissions without directly violating animal rights. Reducing food waste by eating discarded animal-based foods and dumpster diving would represent such situations that divide opinions among veg*ns (see Abbate 2019b; Almassi 2011, and Driver 2016 for vegan and vegetarian objections to such practices). Some animal rights advocates argue that the mere act of eating animal-based food, regardless of origin, is disrespectful and violates animal rights (Abbate 2019b). Although a comparison to the case of eating human flesh (Goodnick 2015) may not be fully convincing, we cannot examine this issue here in detail. It is not clear that eating the already discarded food would any longer be disrespectful towards the animal and some could argue even the opposite: perhaps it is more respectful to become a part of the nutrient cycle than end up in a waste incinerator that is the real alternative for the wasted food. ${ }^{34}$ Another issue is whether the animal rights

\footnotetext{
33 A solely consequentialist viewpoint could lead to the acceptance of animal foods as a part of common diets especially if technical innovations are developed to allow the production of low-/zero-carbon or even carbon-negative animal foods, especially when those can be produced without factory farming. In such cases it could be argued that producing, e.g., zero-carbon meat yields significant benefits that outweigh the costs caused to those animals. This viewpoint may become particularly strong and hard to challenge if the nutritional benefits of small amounts of animal-based foods are included in such consequentialist calculations.

${ }^{34}$ Human and animal cases may not be parallel: animal ethicists rarely call for treating dead animals in a way that humans are demanded to be treated after death (appropriate burial procedures).
} 
approach actually implies the obligation to a fully vegan diet: grounding rights on sentience, for example, may exclude some animals from the sphere of rights.

The Rights First argument has advantages. It resonates with the idea that human rights, too, set limits for permitted actions to mitigate emissions. It helps address one particular risk of low-carbonisation of animal production: entrenched instrumentalisation. Ruminants are a major reason for foodrelated climatic impacts because of their methane burps (Poore and Nemecek 2018). The will to solve challenges technologically increases interest in methane capturing and reuse. Such technologies render ruminants into 'biogas generators', to solve both food and fuel emission challenges. However, it would likely imply keeping the animals indoors (to avoid methane leakages) and increasingly concentrated factory-like operation systems to maximise the biogas benefits and energy efficiency. In addition to animal welfare impacts noted already in empirical studies (Spijker et al. 2019), this would doubly instrumentalise animals who would function both as food and a source of fuel. The Rights First argument would clearly prohibit such solutions, regardless of effectiveness, and protect animals from becoming mere means for climate action. Notably, the argument also shows why a solely consequentialist reasoning about the reduction of climatic or other environmental impacts of food systems may have morally unacceptable consequences.

The Rights First argument has weaknesses, too. First, it speaks only to those who already accept the idea of animal rights. Second, it may not provide a sufficient argument for principled veganism (consider waste food). Third, the problems of conflicts between rights are not taken into account by the argument. Tensions between some human rights and effective climate action are likely to emerge and evoke a difficult question: what if respecting all potentially acknowledgeable human and animal rights prevents the effective climate action needed to avoid dangerous climate change? This consequence, of course, would also violate rights, though within a longer time frame and through more complex mechanisms. Whose rights should be prioritised? How, by whom, and on what grounds should these conflicts be settled?

\section{'Saving' the CAV: call for clear boundaries?}

The advocates of animal-centred, principled veg*nism (not always veganism) also appeal to the idea of clear boundaries that may be easiest to follow and communicate to others (Almassi 2011). The argument is that because various exceptions only complicate things, it is easier and clearer to have a simple principle, 'go veg*n'-that is, vegan, in the context of climate change. From the pragmatic viewpoint, the argument for simplicity is appealing. ${ }^{35}$

Logical consistency, however, does not necessitate (nor guarantee) simplicity. Another, more pragmatic and critical, point is that we are not convinced that principled veganism would be easier to follow despite categorical simplicity. The 'list-of-ingredients' approach to veganism necessitates checking the ingredients of all food items and of meals eaten outside one's home, putting in effort to find suitable foods and sufficient nourishment in situations with limited options, and so on. A less principled 'least harm approach' to veganism, as suggested by Lamey $(2019$, p. 65), is epistemically even more demanding. Instead of these, focusing on the main constituent foods of one's diet (and not worrying about additives and occasional exceptions) would be simpler due to flexibility and sufficient from the emissions viewpoint. Consequently, calling for clear boundaries does not provide a convincing reason for principled veganism on climatic grounds. Interestingly, reasoning that resonates with this flexibility (but is more permissive) has been recently articulated even by Jonathan Safran Foer who is known for actively advocating for the animal cause. Safran Foer writes on climate-friendly eating: "The average US and UK citizen must consume $90 \%$ less beef and $60 \%$ less dairy. No animal products for breakfast or lunch would come close to achieving that. It might not amount to precisely the reductions that are asked for, but it's about right, and easy to remember." ${ }^{36}$

The question of boundaries calls for considering the place of pragmatism in the ethical principles for eating. We have purposely referred to the obligation to reduce one's emissions below a 'harmful threshold' (the definition of which is not just the task of normative reasoning but essentially requires empirical sciences). ${ }^{37}$ This interpretation clearly emphasises sufficient rather than 'climate-optimal' action. It would be an important task for scientists to propose sufficiently clear and easy-to-follow rules of thumb for climatefriendly diets that take local conditions and histories into account in proposing climate-friendly diets. A high-profile example of the latter is the idea of a Planetary Health Diet (Willett et al. 2019). We find the threshold-like approach

\footnotetext{
35 Considerations about simplicity are relevant to any climatic argument for dietary changes and could also be used to construct a noteworthy objection to 'ethical omnivorism' that is probably the epistemically most demanding diet to follow (we'd like to thank one of the reviewers for this observation).

36 The Guardian, 2018: https://www.theguardian.com/books/2019/ sep/28/meat-of-the-matter-the-inconvenient-truth-about-what-we-eat. Such principles may also be practicable for a greater amount of people than veg*nism. Practicability, of course, does not guarantee the moral justifiability of any stance.

37 See Morgan-Knapp and Goodman (2015) for a discussion about various thresholds in climate ethics and Budolfson (2015) for harm footprints in food ethics.
} 
sound and more feasible than arguments obliging the minimisation of one's dietary emissions. Adherence to the minimisation principle would be overly demanding and likely lead to very onerous information acquisition, complex and heavy calculations (and a very simple and light diet). It could also possibly raise a problem of weighing pragmatically between the climatic and nutrition-related goals of the diet as well as between the other ethical aspects that our dietary choices have, including the various demands of justice (Kortetmäki 2019) and the impacts of such endeavours on other aspects of life and ethical obligations therein.

\section{Conclusion}

It is possible to follow veganism as a climate-friendly dietary option, but it is not possible to consistently hold that adherence to a moral obligation to avoid climate-harmful dietary choices would necessitate a vegan (or veg*n) diet. In other words, it is hard to formulate a climatic argument that would convincingly create a moral obligation to strict veganism as a conclusion. We have in this paper evaluated the climatic argument for veganism (implying principled veganism), frequent in contemporary public discourse, and revised the argument to create a more convincing amended climatic argument for veganism. The latter obliges one to follow a predominantly, but not strictly, vegan diet and acknowledges several points for permitted non-vegan actions, like eating (some) fish or eating otherwise discarded foods.

Our main result is that sound arguments for animalconcerned principled veganism and for climate-concerned veganism produce partially different sets of permitted foods. There is a fundamental categorical difference: while veganism is commonly understood to imply a set of food (and other product) prohibitions (Lamey 2019, p. 65), that is to say a categorical criterion, climatic arguments and consequent ethical principles are essentially based on harm footprints and are therefore of a comparative nature (Budolfson 2015). This should be taken into account by those who wish to posit climate-concerned arguments for veganism and are primarily interested about promoting the animal cause and principled veganism. Notably, the arguments for veganism are, nevertheless, more consistent on climatic grounds than arguments for vegetarianism: vegetarianism prohibits the most notable non-vegan low-carbon foods (fish) but permits non-vegan high-carbon foods (cheese).

Some advocates of animal-concerned veganism, those who advocate strict principled veganism, may want to reject the climatic argument and return to the 'traditional' ways of arguing for principled veg*nism on animal-concerned grounds to keep their argumentation sound. They may also appeal to the 'Rights First argument' discussed above (though there are some weaknesses in this appeal). Others may consider adopting a pluralistic approach. This paper involves a strictly climate-oriented analysis. There can be, and indeed are, other reasons for adherence to veg*nism: the traditional ethical views that rest on utilitarian and Kantian ways of thinking. Moreover, there are many other views in favour of veg*nism (though not always in a principled version), from self-regarding health concerns (e.g., Clark et al. 2019) to aspects of the common good including social fairness, efficiency of land use, and ecological sustainability. One can even stick to ecocentric arguments for veg*nism that would grant moral considerability to ecological systems, populations and/or species, rather than to individuals. According to this viewpoint, the appropriation of land for large-scale and/or industrialised animal production degrades values in nature. On the other hand, traditional small-scale herding has produced and still maintains diverse habitats (and highly valued cultural landscapes): there is a potential conflict between non-anthropocentric views on the desirability of cattle keeping in food systems. Notably, even if almost none of the additional concerns listed here (health, social fairness, efficiency, ecocentrism) necessitates a veg*n, let alone a vegan diet, they all point towards endorsing a diet that significantly reduces the role of animals in the industrialised food systems and in Western diets. For some animal-concerned vegans this may not be a desired outcome at the level of individual dietary choices, but for the animal kingdom and for addressing the challenge of climate change it is certainly good news. It is not the number of vegans but the amount of animal production that matters.

Our examination demonstrates broader implications and methodological challenges for the studies in food system values and ethical principles for individual action in these domains. The classical issues of food ethics often pose dichotomous and categorical questions to which one can answer yes or no: one's dietary choices either violate the moral value of animals or they do not. In contrast, the more recent harmful impacts of food systems, whether environmental or social, are practically never dichotomous issues but constitute a continuum ${ }^{38}$ of more or less significant harms about which empirical research informs us. Moreover, the impacts of individual choices do not take place within isolated supply chains but in the broad context of food systems. These challenges pose new kinds of problems for food ethics and the 'traditional' ways to deal with ethical eatingeither on consequentialist or deontological grounds-may provide empirically unsound or counterintuitive answers when their systems-level implications are considered. This era of new food challenges calls for collaboration between

\footnotetext{
38 Previously, Budolfson (2015) and Saja (2013) have proposed moral/harm footprints that vary significantly between different products even within one product category.
} 
ethicists and empirical scientists, leading to better judgments, improved policies, and a more sustainable future for humans and animals.

Acknowledgements We want to thank Miira Tuominen, Mikko Puumala, Helena Siipi, and the anonymous reviewers for useful feedback. This research was supported by The Finnish Strategic Research Council Funding (Grant 327284).

Funding Open access funding provided by University of Jyväskylä (JYU).

Open Access This article is licensed under a Creative Commons Attribution 4.0 International License, which permits use, sharing, adaptation, distribution and reproduction in any medium or format, as long as you give appropriate credit to the original author(s) and the source, provide a link to the Creative Commons licence, and indicate if changes were made. The images or other third party material in this article are included in the article's Creative Commons licence, unless indicated otherwise in a credit line to the material. If material is not included in the article's Creative Commons licence and your intended use is not permitted by statutory regulation or exceeds the permitted use, you will need to obtain permission directly from the copyright holder. To view a copy of this licence, visit http://creativecommons.org/licenses/by/4.0/.

\section{References}

Abbate, C. 2019a. Veganism, (Almost) harm-free animal flesh, and nonmaleficence. In The Routledge handbook of animal ethics, ed. B. Fischer, 555-568. London: Routledge.

Abbate, C. 2019b. Save the meat for cats: why it's wrong to eat roadkill. Journal of Agricultural and Environmental Ethics 32 (1): 165-182. https://doi.org/10.1007/s10806-019-09763-6.

Almassi, B. 2011. The consequences of individual consumption: a defence of threshold arguments for vegetarianism and consumer ethics. Journal of Applied Philosophy 28 (4): 396-411. https:// doi.org/10.1111/j.1468-5930.2011.00544.x.

Almeida, M.J., and M.H. Bernstein. 2000. Opportunistic carnivorism. Journal of Applied Philosophy 17 (2): 205-211. https://doi. org/10.1111/1468-5930.00154.

Bruckner, D. 2016. Strict vegetarianism is immoral. In The moral complexities of eating meat, ed. B. Bramble and B. Fischer, 30-47. New York: Oxford University Press.

Budolfson, M. 2015. Consumer ethics, harm footprints, and the empirical dimensions of food choices. In Philosophy comes to dinner: arguments over the ethics of eating, ed. A. Chignell, T. Cuneo, and M.C. Halteman, 163-181. New York: Routledge.

Clark, M., and D. Tilman. 2017. Comparative analysis of environmental impacts of agricultural production systems, agricultural input efficiency, and food choice. Environmental Research Letters 12 (6): 064016. https://doi.org/10.1088/1748-9326/aa6cd5.

Clark, M.A., M. Springmann, J. Hill, and D. Tilman. 2019. Multiple health and environmental impacts of foods. Proceedings of the National Academy of Sciences 116 (46): 23357-23362.

Driver, J. 2016. Individual consumption and moral complicity. In The moral complexities of eating meat, ed. B. Bramble and B. Fischer, 67-79. New York: Oxford University Press.

Goodnick, L. 2015. Limits on locavorism. In Just food: philosophy, justice and food, ed. J.M. Dieterle, 195-211. London: Rowman and Littlefield.
Henning, B. 2011. Standing in livestock's 'long shadow': the ethics of eating meat on a small planet. Ethics \& the Environment 16 (2): 63-93.

Henning, B.G., and Z. Walsh, eds. 2020. Climate change ethics and the non-human world. London: Routledge.

IPCC, 2018: Summary for Policymakers. In: Global Warming of $1.5^{\circ} \mathrm{C}$. An IPCC Special Report on the impacts of global warming of $1.5^{\circ} \mathrm{C}$ above pre-industrial levels and related global greenhouse gas emission pathways, in the context of strengthening the global response to the threat of climate change, sustainable development, and efforts to eradicate poverty. Masson-Delmotte, V., P. Zhai, H.-O. Pörtner, D. Roberts, J. Skea, P.R. Shukla, A. Pirani, W. Moufouma-Okia, C. Péan, R. Pidcock, S. Connors, J.B.R. Matthews, Y. Chen, X. Zhou, M.I. Gomis, E. Lonnoy, T. Maycock, M. Tignor, and T. Waterfield (eds.). World meteorological organization, Geneva, Switzerland, p. 32

Kain, P. 2018. Kant of animals. In Animals: a history, ed. P. Adamson and G.F. Edwards, 211-232. Oxford: Oxford University Press.

Korsgaard, C.M. 2018. Fellow creatures. Our obligations to the other animals. Oxford: Oxford University Press.

Kortetmäki, T. 2019. Nobody's fault? Structural Injustice, food, and climate change. In Food, environment, and climate change, ed. E. Gilson and S. Kenehan, 47-61. New York: Rowman and Littlefield.

Lamey, A. 2019. Duty and the beast: should we eat meat in the name of animal rights? Cambridge: Cambridge University Press.

McShane, K. 2016. Anthropocentrism in climate ethics and policy. Midwest Studies in Philosophy 40: 189-204.

Morgan-Knapp, C., and C. Goodman. 2015. Consequentialism, climate harm and individual obligations. Ethical Theory and Moral Practice 18: 177-190.

Newmyer, S.T. 2006. Animals, rights and reason in Plutarch and modern ethics. London: Routledge.

Norcross, A. 2004. Puppies, pigs, and people: eating meat and marginal cases. Ethical Perspectives 18: 229-245.

Pepper, A. 2019. Adapting to climate change: what we owe to other animals. Journal of Applied Philosophy 36 (4): 592-607.

Petter, O. 2018. Veganism is 'single biggest way' to reduce our environmental impact on planet, study finds. Independent June 1, 2018.

Poore, J., and T. Nemecek. 2018. Reducing food's environmental impacts through producers and consumers. Science 360: 987-992.

Regan, T. 1988. The case for animal rights. London: Routledge.

Roht-Arriaza, N. 2009. First, do no harm: human rights and efforts to combat climate change. Georgia Journal of International \& Comparative Law 38: 593.

Saja, K. 2013. The moral footprint of animal products. Agriculture and Human Values 30: 193-202. https://doi.org/10.1007/s1046 0-012-9402-x.

Sandler, R.L. 2015. Food ethics: the basics. London: Routledge.

Scarborough, P., P.N. Appleby, A. Mizdrak, A.D. Briggs, R.C. Travis, K.E. Bradbury, and T.J. Key. 2014. Dietary greenhouse gas emissions of meat-eaters, fish-eaters, vegetarians and vegans in the UK. Climatic Change 125 (2): 179-192.

Sidgwick, H. 1906. The methods of ethics. [7th ed. without publication year] Indianapolis: Hackett.

Singer, P. 1980. Utilitarianism and vegetarianism. Philosophy \& Public Affairs 9 (4): 325-337.

Singer, P. 2016. Afterword. In The ethics of killing animals, ed. T. Višak and R. Garner, 229-235. Oxford: Oxford University Press.

Sinnott-Armstrong, W. 2005. It's not my fault: global warming and individual moral obligations. In Perspectives on climate change, ed. W. Sinnott-Armstrong and R. Howarth, 221-253. Amsterdam: Elsevier.

Spijker, E., A. Anger-Kraavi, H. Pollitt, and D. van de Ven. 2019. Evaluating integrated impacts of low-emission transitions in the 
livestock sector. Environmental Innovation and Societal Transitions. https://doi.org/10.1016/j.eist.2019.11.003.

Taylor, P.W. 1986. Respect for nature. Princeton, NJ: Princeton University Press.

Voget-Kleschin, L., C. Baatz, and L. Garcia-Portela. 2019. Introduction to the special issue on individual environmental responsibility. Journal of Agricultural and Environmental Ethics 32: 493-504. https://doi.org/10.1007/s10806-019-09792-1.

Wenz, P.S. 1984. An ecological argument for vegetarianism. Ethics and Animals 5: 4.

Willett, W., J. Rockström, B. Loken, M. Springmann, T. Lang, S. Vermeulen, and L. MajeleSibanda. 2019. Food in the Anthropocene: the EAT-lancet commission on healthy diets from sustainable food systems. The Lancet 393 (10170): 447-492.

Wirsenius, S., F. Hedenus, and K. Mohlin. 2011. Greenhouse gas taxes on animal food products: rationale, tax scheme and climate mitigation effects. Climatic Change 108: 159-184.

Ziegler, F., U. Winther, E.S. Hognes, A. Emanuelsson, V. Sund, and H. Ellingsen. 2013. The carbon footprint of norwegian seafood products on the global seafood market. Journal of Industrial Ecology 17: 103-116. https://doi.org/10.1111/j.1530-9290.2012.00485.x.
Publisher's Note Springer Nature remains neutral with regard to jurisdictional claims in published maps and institutional affiliations.

Teea Kortetmäki (PhD) is a postdoctoral researcher at the University of Jyväskylä, JYU.Wisdom School of Resource Wisdom. Her research interests include environmental and food ethics and sustainable food systems. Currently, she studies the conceptualisation of and conditions for the just sustainability and low-carbon transitions in food systems.

Markku Oksanen (DSocSc) is a Senior Lecturer in Philosophy at the University of Eastern Finland. He has published widely on green political theory and environmental ethics, including edited volumes Philosophy and Biodiversity (Cambridge, 2004), The Ethics of Animal Re-creation and Modification (Palgrave, 2014) and Environmental Human Rights (Routledge, 2018). 